\title{
Correction to: Sickness absence trajectories following labour market participation patterns: a cohort study in Catalonia (Spain), 2012-2014
}

Julio C. Hernando-Rodriguez ${ }^{1,2,3}$, Laura Serra ${ }^{4^{*}}$, Fernando G. Benavides ${ }^{1,2,3}$ and Monica Ubalde-Lopez ${ }^{5}$

\section{Correction to: BMC Public Health (2020) 20:1306 https://doi.org/10.1186/s12889-020-09396-9}

It was highlighted that in the original article [1] the legends of Figs. 1 and 2 were interchanged. This Correction article shows the Fig. 1 and Fig. 2 with their correct legends. The original article has been updated.

\footnotetext{
Author details

${ }^{1}$ Center for Research in Occupational Health (CiSAL), Pompeu Fabra University, Barcelona, Spain. ${ }^{2}$ CIBER of Epidemiology and Public Health (CIBERESP), Madrid, Spain. ${ }^{3} \mathrm{IMIM}$ - Parc Salut Mar, Barcelona, Spain. ${ }^{4}$ GREC S-Research Group on Statistics, Econometrics and Health, Faculty of Economics and Business, University of Girona (UdG), C/ Universitat de Girona, 10, 17071 Girona, Spain. ${ }^{5}$ Barcelona Institute for Global Health (ISGlobal), Barcelona, Spain.
}

Published online: 01 October 2020

\footnotetext{
Reference

1. Hernando-Rodriguez JC, et al. Sickness absence trajectories following labour market participation patterns: a cohort study in Catalonia (Spain), 20122014. BMC Public Health. 2020;20:1306. https://doi.org/10.1186/s12889-02009396-9.
}

\footnotetext{
The original article can be found online at https://doi.org/10.1186/s12889020-09396-9.

*Correspondence: laura.serra@udg.edu

${ }^{4}$ GRECS-Research Group on Statistics, Econometrics and Health, Faculty of

Economics and Business, University of Girona (UdG), C/ Universitat de Girona,

10, 17071 Girona, Spain

Full list of author information is available at the end of the article
}

(c) The Author(s). 2020 Open Access This article is licensed under a Creative Commons Attribution 4.0 International License, which permits use, sharing, adaptation, distribution and reproduction in any medium or format, as long as you give appropriate credit to the original author(s) and the source, provide a link to the Creative Commons licence, and indicate if changes were made. The images or other third party material in this article are included in the article's Creative Commons licence, unless indicated otherwise in a credit line to the material. If material is not included in the article's Creative Commons licence and your intended use is not permitted by statutory regulation or exceeds the permitted use, you will need to obtain permission directly from the copyright holder. To view a copy of this licence, visit http://creativecommons.org/licenses/by/4.0/. The Creative Commons Public Domain Dedication waiver (http://creativecommons.org/publicdomain/zero/1.0/) applies to the data made available in this article, unless otherwise stated in a credit line to the data. 


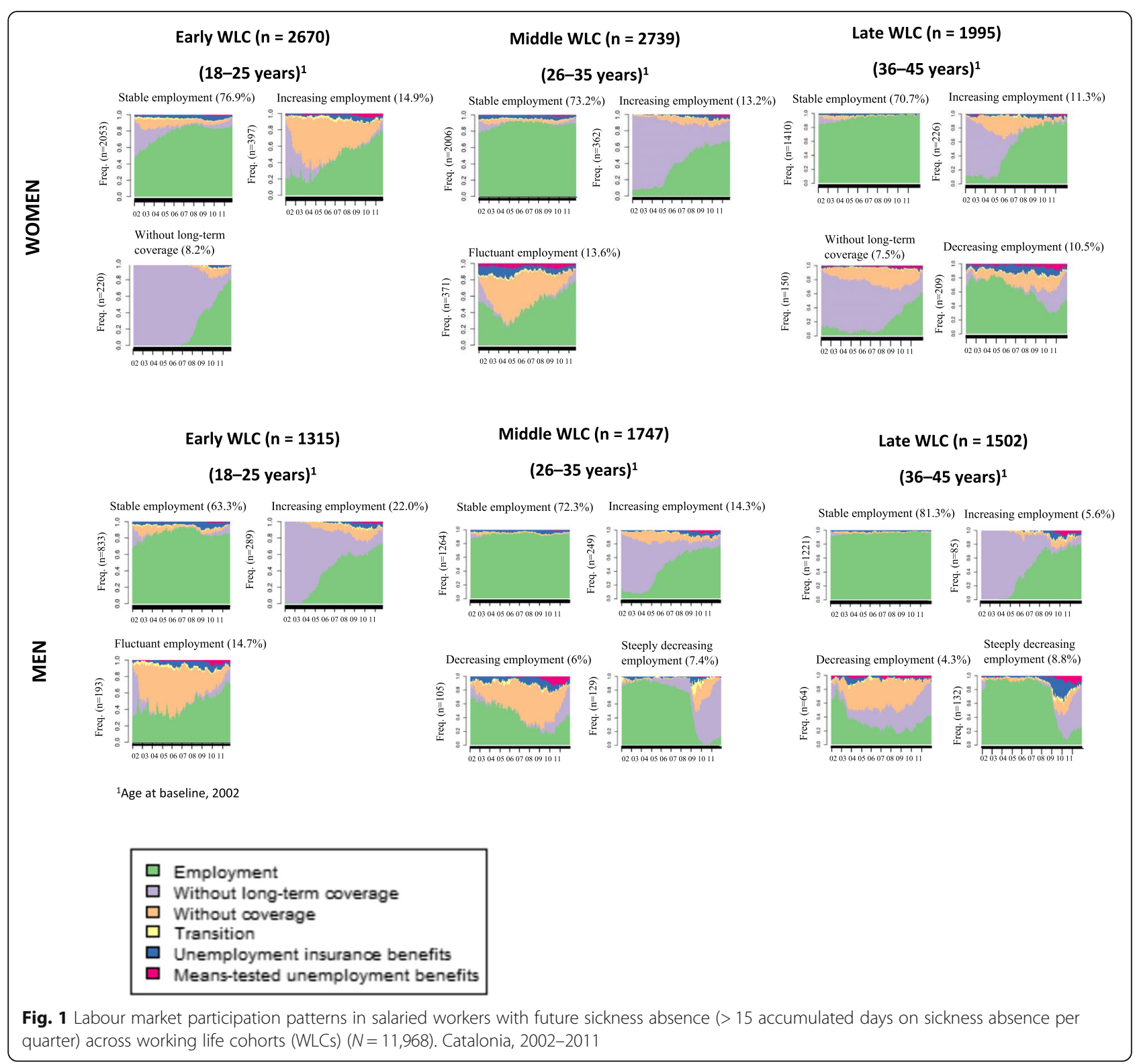




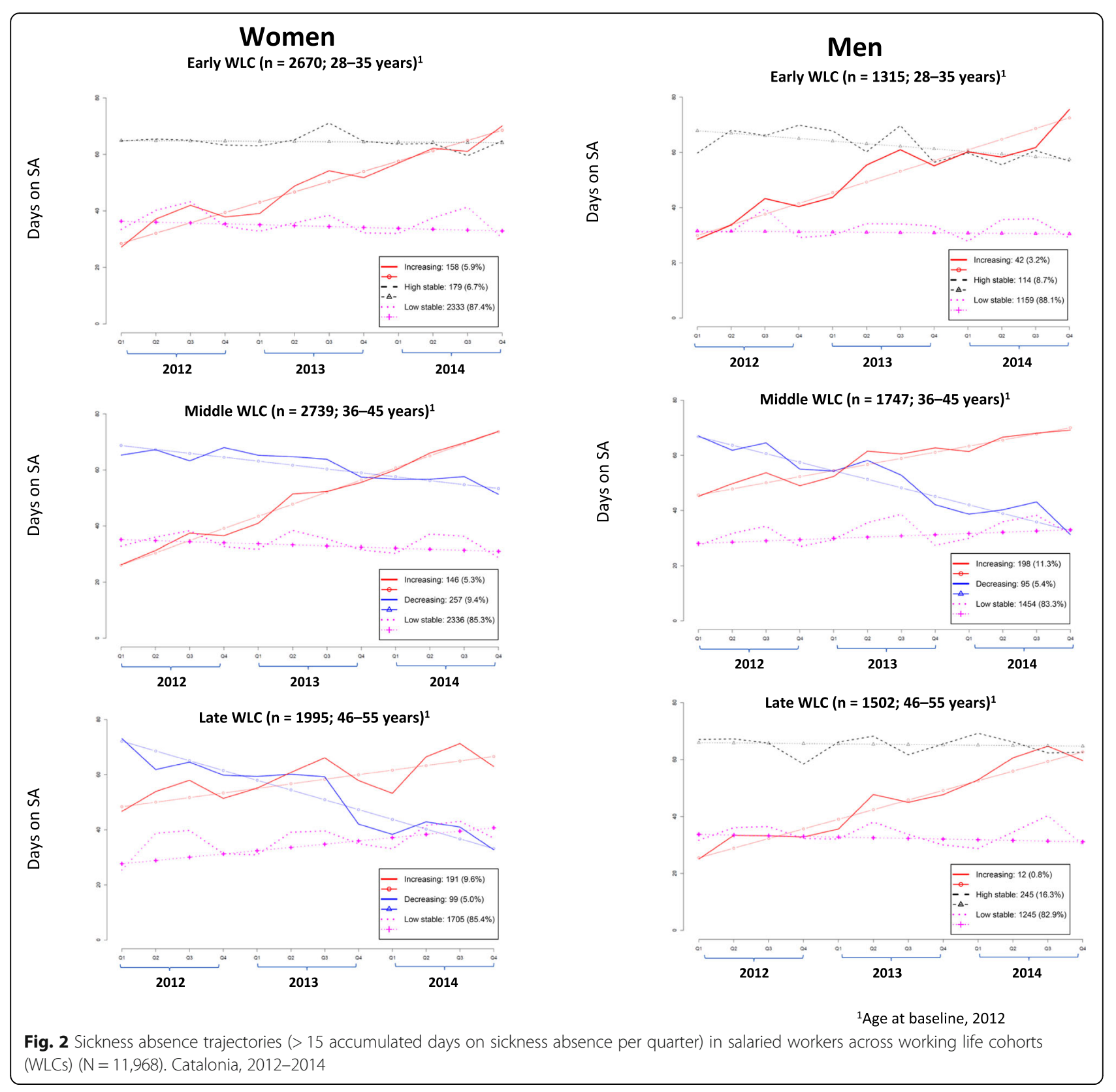

